\title{
Errors, Durable and Otherwise
}

\author{
CHARLES TILLY
}

\section{Columbia University}

Social life consists of making mistakes, then correcting them. The big questions do not concern who makes the fewest mistakes and why, but whether the mistakes are fruitful, how fast people recognize them, and how well they correct them. The same principles apply to writing books, even if the interaction and error-correction take longer to operate than in everyday conversation. This symposium's vigorous, vital critiques of Durable Inequality establish that my book is no exception to the rule. Clearly in writing the book I made mistakes of at least four kinds:

- failing to anticipate certain misunderstandings it was likely to generate;

- failing to emphasize the heuristic character of some exaggerated contrasts;

- failing to explicate its explanatory strategy in sufficient detail;

- failing to develop the view of interactions among individual experience, history, culture, and social relations on which it depends.

I am grateful to CSSH and its critics for an opportunity to correct some of these mistakes.

A reader of Erik Wright's critique might forgivably imagine Durable Inequality to be a ponderous tome of general theory. Aldon Morris' readers could easily suppose that the book concentrates on explaining contemporary inequalities in the United States. Meanwhile, readers of Barbara Laslett might well conclude that aside from Mamaroneck's Bossi family the book features no strivings of real people. To dispel those illusions, let me describe the book. It first took shape as a series of lectures at UCLA, lectures inspired by the work that Chris Tilly and I were doing simultaneously on a companion book, Work Under Capitalism. The latter book uses a synthesis of Marxist and institutional ideas to build a relational account of capitalist work and labor markets, illustrating its arguments chiefly with evidence from the contemporary United States. Work Under Capitalism deals with work in households, neighborhoods, and many other settings outside of formally organized firms. Writing Durable Inequality at the same time gave me a chance to elaborate ideas about inequality, and to include material from far outside the contemporary United States that kept muscling into my contributions to the father-son effort.

Both books rely on weak functionalist arguments. Strong functionalist arguments characteristically explain social phenomena by their consequences for the system in which they occur, for example by arguing that welfare institutions 
exist because they sustain capitalism. They have properly gained a bad reputation for circularity, teleology, and invulnerability to verification or falsification. Weak functionalist arguments claim that actors pursuing certain ends try out various means to those ends, then tend to adopt those means that: a) accomplish those ends, and b) reinforce the set of arrangements within which the pursuit of those ends remains possible.

Within exploitation, as Erik Wright points out, the argument says that sets of people who control value-producing resources tend to create or adopt social relations not only channeling to themselves some of the value added by the effort of others with respect to those resources, but also reinforcing the command structures that maintain the exploiters' positions. (The argument does not require that participants be sharply aware of ends, means, and feedback, but simply that they be engaged in self-reproducing social arrangements.) Such weak functionalist arguments have the virtue of being readily falsifiable if wrong.

Durable Inequality takes eight chapters and 246 pages to explain how such an approach relates to previous analyses, lay out the basic analytic scheme, discuss the operation of categories, present and illustrate basic mechanisms, apply the arguments to large-scale political change, and speculate about future inequalities. The book's arguments center, as Wright says, on the articulation between basic patterns of social relations - chains, triads, categorical pairs, and their elaborations - and mechanisms of exploitation, opportunity hoarding, emulation, and adaptation. Its explanations center, as Wright likewise says, on Marxist conceptions of exploitation.

The book overflows with examples and applications. Those occupying a page or more include statures of English youths around 1800, disputes generated by Herrnstein and Murray's Bell Curve, monetary transfers in the twentiethcentury United States, family feeding patterns, stigmatization of paupers in late medieval Europe, ethnic relations in South African mines, categorical divisions among the nineteenth-century Tshidi, South African apartheid and its transformations, Rosabeth Kanter's Indsco, treatment of female cadets at the Citadel, Italian migrants to Mamaroneck, migration of my mother's family to the U.S., European nationalism since 1559, professionalization of American medicine since 1850, oppression of African-Americans, Catholic Emancipation in Great Britain (1688-1829), and development of citizenship in western countries. Dozens more occupy less than a page. Whatever its other failings, the book certainly provides concrete instances of the human experiences it analyzes. It also ranges far beyond contemporary American business.

It is true, to be sure, that none of these examples constitutes evidence in any strong sense of the word. I believe in evidence, and have written many books confronting far simpler arguments than those of Durable Inequality with great heaps of historical evidence. This book, however, concentrates on laying out a general set of explanations for inequality and its changes, then illustrates those explanations just enough to make their implications clear. The book's explana- 
tions do not take the form of general laws, comprehensive models of social development, or representations of entire societies. Instead, they center on identification of a crucial set of causal mechanisms that in different combinations, and with variable but comprehensible outcomes, play parts in the generation and transformation of durable inequality everywhere and at all times. That such an effort fails in the present state of our knowledge goes without saying. The question is how well it fails.

It is also true that the book offers an incomplete, hesitant synthesis between universalist and historicist analyses. On one side, it claims to identify similarities among inequality-generating mechanisms across an enormous range of times and places. On the other, it claims that how mechanisms concatenate and what large-scale effects they produce both depend on the cultural milieu in which they operate. In fact, the particularity and familiarity of cultural forms figure directly in the book's explanations of how its basic mechanisms work. Adaptation, for example, depends heavily on local knowledge, on the capacity of people to thread previously acquired practices, representations, understandings, and social relations into unequal structures. Again, the question is not whether the book's synthesis of universalist and historicist views solves all its problems, but how well it fails.

Consider the major failings identified by our three critics. The book, one or more of them claims,

- misrepresents available alternatives to its views;

- underestimates or misrepresents the power of beliefs;

- exaggerates the place of formal organizations in the production of inequality;

- misses exploitation as a source of racial inequality;

- belittles or misconstrues inheritance as a source of inequality;

- belittles human agency.

Let me review each of the alleged failings in turn before reflecting more generally on issues the critics raise.

Does the book misrepresent its adversaries? Yes and no. Yes: in a strategy reminiscent of the very categorical phenomena it analyzes, it sweeps a variety of approaches into a box called "individualism." The approaches discussed range from strict atomism to the subtle placing of individual decisions in rich institutional contexts by such analysts as Avner Greif, Jon Elster, and Erik Wright himself. That heuristic compression dramatizes the book's situation of genuine causes in continuously-negotiated social interaction, rather than in individual deliberation. It calls attention to the central place of relational (rather than cognitive or environmental) causal mechanisms in social life. It places exploitation, opportunity hoarding, emulation, and adaptation in the company of relational mechanisms such as brokerage and coalition formation.

The book's heuristic flattening of various individualisms does not, however, manufacture a difference where none exists. Recent institutionalist concessions that existing social relations, culture, and institutions constrain individual 
decision-making all constitute steps in the right direction, but do not represent a full-fledged incorporation of dynamic interaction into explanations of social processes. The richest rational choice analyses still lack theories of consequences: accounts of how individual decisions produce their effects. They are unlikely to produce satisfactory theories of consequences until they take serious account of relational mechanisms. In any case, recent institutionalist views have barely touched prevailing explanations of inequality. Today's dominant explanations center on individuals varying in attributes and propensities, who pass through selection points at which other individuals (justly or unjustly) channel them into unequal positions. Durable Inequality takes great pains to criticize, reject, and replace such explanations.

Does the book minimize or misrepresent the effects of beliefs on inequality? Maybe. It argues strenuously against the common idea that bad attitudes cause inequality, and therefore that correction of bad attitudes removes inequality. It claims that organizational processes frequently commit people, including victims of exploitation and opportunity hoarding, to deeply unequal social arrangements in the absence of profound prejudice. It attributes great potential leverage to organizational changes involving little or no prior alteration of attitudes - in fact, organizational changes of the very kinds that Aldon Morris invokes in criticism of the book's arguments.

On the other side, however, Durable Inequality also argues that categorical boundaries have histories of their own; gender distinctions, for example, accumulate understandings, practices, and representations that make them operate rather differently from distinctions by class, race, and ethnicity. Indeed, that cultural accumulation accounts in part for the efficacy of emulation as a mechanism: understandings, practices, and representations are already available for transplantation into new settings. To the extent that particular configurations of understandings, practices, and representations differ in their effects on people's interchanges within unequal social relations, goes the argument, beliefs actually matter.

Fortunately, the problem lends itself to adjudication by standard procedures of social science and comparative history. We must investigate situations in which similar organizational changes occurred in the presence of substantially different cultures of inequality, or in which major alterations of beliefs occurred in the absence of significant organizational transformations. Such investigations could support the Morris-Laslett objection that I underestimate the autonomous power of beliefs and attitudes. I doubt that they will.

Does the book exaggerate the centrality of formal organizations to inequality? Here is the book's introduction to organizations:

Although the word "organization" may call to mind firms, governments, schools, and similar formal, hierarchical structures, I mean the analysis to encompass all sorts of wellbounded clusters of social relations in which occupants of at least one position have the right to commit collective resources to activities reaching across the boundary. Organi- 
zations include corporate kin groups, households, religious sects, bands of mercenaries, and many local communities. Durable inequality arises in all of them (9-10).

Organizations, then, range very widely, certainly far beyond capitalist firms. The list of examples cited earlier should allay the suspicion that the book takes today's capitalist firms as the model for all inequality everywhere.

Yet once again a heuristic strategy helps explain the misunderstanding. The greatest volume of recent social scientific work on inequality has, indeed, focused on work within capitalist firms. When it comes to confronting alternative views on their own grounds, or reaching for systematic contemporary examples, therefore, I frequently turn to occupational hierarchies, job segregation within firms, segmented labor markets, wage differentials, and similar welldocumented phenomena. It will, indeed, take much more effort to see how much revision or elaboration the book's explanatory schemes will require when seriously applied outside the range of today's capitalism.

Does the book miss the significance of exploitation for racial inequality? The major case analyzed in the chapter on exploitation is South African apartheid. In South Africa, European exploiters did not merely subjugate Africans to their rule: they invented, imposed, enforced, and revised racial categories as they created new ways of drawing surplus value from African effort. In North America, apartheid never reached quite the sharpness of division or the degree of legal inscription that prevailed in South Africa between 1950 and 1980. Yet white exploitation did, as Aldon Morris insists, significantly promote black subjugation in the United States as well. The only puzzle, indeed, is why he thinks the book argues otherwise.

Does the book misconstrue inheritance as a cause of inequality? It treats inheritance as a crucial version of opportunity hoarding. Here is the central passage on the subject in the chapter on opportunity hoarding:

We can make a rough distinction between forms of opportunity hoarding that attach their participants directly to an exploiting organization and those that bear only contingent or indirect relations to exploitation. The creation of immigrant niches within manufacturing firms falls emphatically into the first set, regardless of the extent to which the immigrants themselves benefit or suffer from exploitation. A firm or an alliance of firms that establishes monopoly or oligopoly over production and sale of a given commodity simultaneously practices exploitation within firm boundaries and opportunity hoarding with respect to all other potential producers and sellers.

More contingent and indirect (albeit powerful) relations of opportunity hoarding to exploitation stem from inheritance within households, kin groups, and ethnic categories. Under capitalism, inequality in regard to inherited wealth generally exceeds inequality in regard to monetary income, since the wealthy customarily draw important returns from their wealth in nonmonetary forms and hoard some portion for transmission to heirs. As income inequality has sharpened in the United States during the past two decades, wealth has become even more unequally distributed. Clever lawyers and a favorable tax regime have made it easy for America's wealthy to retain their property from generation to generation. In this case, beliefs in wealth as property, in the inviolability 
of property rights, and in the priority of interpersonal ties based on birth and marriage all reinforce the centrality of inheritance as a mode of opportunity hoarding (155-56).

In this case, I plead not guilty.

Does the book belittle human agency, as Barbara Laslett complains? "He denies," Laslett declares, "that people who occupy and activate organizational categories can cause social inequality or that policies oriented toward social change can substantially affect it. As a consequence, he rejects the idea that the actual people who occupy these categories and whose practices construct them under concrete historical, cultural, and organizational conditions are relevant to his theoretical model." A profound misunderstanding has occurred. Durable Inequality scintillates with human agency. As Erik Wright's explication implies, interacting people produce all of its cause-effect relations. What is at issue is not whether human agents cause inequality and its changes, but how they do so. This may be the offending passage:

People who create or sustain categorical inequality by means of the four basic mechanisms rarely set out to manufacture inequality as such. Instead they solve other organizational problems by establishing categorically unequal access to valued outcomes. More than anything else, they seek to secure rewards from sequestered resources. Both exploitation and opportunity hoarding provide a means of doing so. But, once undertaken, exploitation and opportunity hoarding pose their own organizational problems: how to maintain distinctions between insiders and outsiders; how to ensure solidarity, loyalty, control, and succession; how to monopolize knowledge that favors profitable use of sequestered resources. The installation of explicitly categorical boundaries helps to solve such organizational problems, especially if the boundaries in question incorporate forms of inequality that are already well established in the surrounding world. Emulation and adaptation lock such distinctions into place, making them habitual and sometimes even essential to exploiters and exploited alike (11).

The passage reeks of human agency, but treats the production of inequality as an outcome, sometimes unintended, of other pursuits. It thereby denies general explanations of inequality in terms of hate, contempt, mistaken beliefs, or urges to domination for its own sake. It also implies that reduction or alteration of inequality requires organizational change. The real dispute may therefore go back to the relative importance of individual sentiments, beliefs, or orientations as causes of social processes.

Behind this dispute lies a disagreement about explanation. In social science and history, three styles of explanation generally compete. The first expects social life to exhibit empirical regularities that at their highest level take the form of laws. Explanation then consists of subsuming particular cases under broadly validated, empirical generalizations, or even universal laws. The second accounts for particular features of social life by specifying their connections with putative larger entities: societies, cultures, mentalities, capitalist systems, and the like. Explanation then consists of locating elements within systems. The third regards social units as self-directing, whether driven by emotions, motives, interests, rational choices, genes, or something else. Explanation then 
consists of reconstructing the state of the social unit-for example, an individual's beliefs at a given point in time and space - and plausibly relating its actions to that state. (A fourth view declares on epistemological or ontological grounds that no valid explanations of social life or individual behavior are possible in principle, but none of my critics takes that position.)

Durable Inequality rejects all these models of explanation in favor of another view. It claims that explanation consists of identifying reliable causal mechanisms and processes of general scope within particular social phenomena. Causal mechanisms are events that alter relations among some set of elements. Processes are frequent (but not universal) combinations and sequences of causal mechanisms. Social mechanisms are sometimes cognitive, involving changes in perception, consciousness, or intention. They are sometimes relational, involving shifts in connections among social units. They are also sometimes environmental, involving alterations in the surroundings of social units. Explanation then consists of locating robust cognitive, relational, and environmental mechanisms within observed episodes. In practice, no explanation in this mode can ever be complete. But, I claim, it can be far more adequate than subsumption of whole episodes under empirical generalizations, search for locations of units within larger systems, or reconstruction of the social unit's state before and during the initiation of some action.

Without for a moment denying the efficacy of cognitive and environmental mechanisms, Durable Inequality builds its analysis around relational mechanisms: exploitation, opportunity hoarding, emulation, and adaptation. It shows how those mechanisms work, and how they interact. It then compounds them into a few recurrent processes-for example, the frequent incorporation into organizations of ostensibly irrelevant divisions by gender, ethnicity, and/or race. Finally, it proposes partial explanations of complex episodes (e.g., changes in South African apartheid and the migration of my mother's family from Wales to Chicago) by locating robust mechanisms and recurring processes within those episodes. My critics apparently found this explanatory strategy inadequate or baffling.

Where did I go wrong? Perhaps I should have written another book first. That imaginary book would have presented, illustrated, and defended the explanatory strategy without entering the complexities of durable inequality. It would have traced genealogies for the strategy, offered sustained critiques of its rivals, and laid down practical suggestions for its use. It would have applied the strategy to familiar material such as the European popular struggles on which I have previously spilt so much ink. My principal error, no doubt, was to imagine that readers had already become impatient with general law, system relation, and situational reconstruction explanations, and would therefore welcome another way of thinking about how to explain social life. Let me hope that my mistake, and the responses it generated, will help other scholars do better. 